Article

\title{
Synthesis and Characterisation of Organo-Modified Silica Nanostructured Films for the Water-Repellent Treatment of Historic Stone Buildings
}

\author{
Cristian Petcu ${ }^{1, *(\mathbb{D})}$, Elvira Alexandrescu ${ }^{1}$, Adriana Bălan ${ }^{2}$, Maria Antonia Tănase ${ }^{3}$ and \\ Ludmila Otilia Cinteză ${ }^{3, *}$ \\ 1 National Institute for Research and Development in Chemistry and Petrochemistry-ICECHIM, Spl. \\ Independentei 202, 060021 Bucharest, Romania; elvira.alexandrescu@icechim-pd.ro \\ 2 3NanoSAE Research Center, Physics Department, University of Bucharest, 405 Atomistilor Street, PO Box \\ MG-38, 077125 Magurele, Romania; andronie@3nanosae.org \\ 3 Physical Chemistry Department, University of Bucharest, 4-12 Elisabeta Blvd., 030118 Bucharest, Romania; \\ maria.a.tanase@gmail.com \\ * Correspondence: cpetcu@chimfiz.icf.ro (C.P.); ocinteza@gw-chimie.math.unibuc.ro (L.O.C.); \\ Tel.: +40-21-3153676 (L.O.C.)
}

Received: 17 September 2020; Accepted: 18 October 2020; Published: 21 October 2020

\begin{abstract}
This study presents the facile sol-gel synthesis of nanostructured coatings for use in water-repellent treatment of travertine stone. The synthesized materials combine surface roughness characteristics with particular chemical compositions to give different hydrophobicity results. The influence of the silica particle coating precursor on the hydrophobicity of the polymeric film was investigated, and the octyl-modified silane was selected for further fabrication of the hybrid coatings. The water repellent properties, together with composition and structural properties of the silane-based hybrid material were measured on model glass surface. The coating with the best characteristics was subsequently deposited onto the travertine stone. The potential applicability of the nanostructured material was evaluated considering both the properties of the coating film and those of the travertine stone subjected to the treatment. The surface texture of the film, water repellent properties and uniformity were determined using scanning electron microscopy, atomic force microscopy, dynamic light scattering and contact angle measurements. The coating's potential for use in stone conservation was evaluated by assessing its impact on the stone's visual aspect. All the results obtained from the different types of analyses showed that the octyl-modified silica nanostructured material was highly hydrophobic and compatible both with the travertine stone and with the requirements for use on cultural heritage monuments.
\end{abstract}

Keywords: nanostructured coating; organo-modified silica; hydrophobic coating; cultural heritage preservation

\section{Introduction}

Despite the countless efforts made by the international community to preserve heritage monuments, even those built of stone are subject to the constant and inevitable processes of degradation. International monitoring programmes, especially in the last decade, proved the necessity of applying specific treatments for the preservation of these monuments, subjected to weathering, pollution, climate change and other aggressive factors [1].

One of the most commonly used stones in historic monuments all over the world is travertine. This is a dense, finely crystalline limestone with various colours, from white to cream and pale tan. It usually has a fibrous or concentric structure and splintery fracture [2]. Travertine is a natural chemical 
precipitate of carbonate deposited from the water of mineral springs saturated with dissolved acid calcium carbonate. This causes the stone to have pitted holes in its surface [3]. The importance of this building material resides from its wide use for monuments and civil construction since Roman times until the present day, both as a structural stone and in facade decoration or art-works such as sculptures [3]. The main deterioration factors for these monuments, which are on display outside close to industrialized areas, are pollution, possible acts of vandalism, temperature variations and, especially, water contact effects. Thus, the development of new materials for the preservation of stone is a task of great importance in order to offer a suitable tool for the protection against physical, chemical and biological attacks. Significant consideration must be shown for the protection of the works of art located in highly polluted urban areas, for example, the monumental art works of Constantin Brancusi's "The Gate of the Kiss" and "The Table of Silence" made of porous travertine stone that periodically need cleaning procedure due to fungal staining and dirt deposition [4].

The presence of water in these structures of calcareous stones cause damage via three main mechanisms:

- Successive wetting and drying leads to the dissolution and recrystallization of some salts, a process which decisively contributes to the erosion of the support, thus affecting the resistance of the monuments [5];

- Water absorption through capillarity in the porous structure of the stone, followed by freezing, leads to the mechanical destruction of the stone [6];

- Humidity favours the development of bacteria and fungi, the presence of which has a great effect on the material, modifying its colour and gloss [7].

Over the last decades, many water repellent materials were studied as protecting treatments, for consolidation and other restoration purposes [8]. However, the development of such materials is still a challenge, as the characteristics of stones from historical monuments vary widely in origin, processing method, degradation state, and the specific weathering conditions or particular pollution patterns in the area. The particular requirements of the restoration field must not be neglected, as they entail that the applied treatment must be reversible and modify as little as possible the original appearance of the stone in order not to alter the aesthetic value of the monument. Therefore, it is necessary to understand the material's behaviour as well as the stone preservation needs and conditions. Trends in the design of protective treatments for stone monuments and artistic works focus on the use of nanoparticles that ensure a superhydrophobic and photocatalytic effect. Most of the nanoparticles used in superhydrophobic modification of coatings are silica due to the fact of their simplicity in fabrication, stability, and tunable size and shape. Such coatings were successfully applied on various lithotypes, from marble to sandstone and granite [9].

For the conservation of calcareous stone historic monuments, such as those made of travertine, a protective treatment that leads to a highly hydrophobic or superhydrophobic surface was considered the best solution [8].

Protective materials with water repellent properties that are most commonly used in cultural heritage conservation can be divided into four groups [10]: (a) acrylic resins [11], (b) silicone resins (alkylalkoxysilanes or polyalkyl alkoxysiloxanes) [12], (c) combinations of acrylic resins and silicones [8], and (d) fluorinated polymers (fluorinated acrylates, perfluoro-polyethers and perfluor-polyolephines) [13]. Each of them exhibits advantages and specific disadvantages; none of them are considered the best solution for every cultural heritage monument. For common industrial purposes, a facile and convenient way to obtain superhydrophobic surfaces with remarkable chemical stability and enhanced mechanical robustness is based on various fluorinated polymers as coating materials [14]. However, the utilisation of fluorinated compounds in the composition of materials used in the protection of buildings in very large areas containing historical monuments is restricted because of its exceptionally high cost and toxicity when in direct contact with the environment. 
The purpose of this study was to obtain new highly hydrophobic film-forming materials and evaluate their ability to provide water repellent properties to travertine stone. A suitable material for superhydrophobic treatments for historic stone buildings could be designed based on a satisfactory optimisation of the molecular structure and of the morphology [15]. One of our aims was to avoid the use of fluorinated polymers, already widely applied in superhydrophobic industrial treatments [16], due to the concerns about the toxic air contaminants that result in thermal processing and the long-term impact of their release in various ecosystems [17].

The goal of this research was to create a material that would be hydrophobic both due to the fact of its roughness and to the presence of hydrocarbonate chains on the surface but in a different manner than by mixing preformed silica particles with an existing polymer matrix, in an appropriate solvent [18]. A rational approach was used to design the synthesis of the material based on the presumption that a dispersion consisting of silica nanoparticles with an organic-modified surface will ensure the best hydrophobic properties to the film deposited onto the stone's surface with the maximum compatibility and the minimum changes in optical properties.

\section{Materials and Methods}

Tetraethylortosilicate (TEOS) (Fluka reagent, Buchs, Switzerland) was used as the silane precursor for the nanoparticles' preparation through the sol-gel method. Organo-modified silane derivatives were used as secondary reagents in hybrid materials without further purification: methyltriethoxysilane (MTES), vinyltriethoxysilane (VTES), n-triethoxyoctylsilane $\left(\mathrm{O}_{8}\right.$ TES) (all Fluka reagents) and n-octadecyltriethoxysilane $\left(\mathrm{O}_{18} \mathrm{TES}\right)$ were kindly gifted by Gelest Inc. Ethanol $(>99.9 \%$, Merck, Darmstadt, Germany) and distilled water were used as reaction solvents. Ammonium hydroxide (Sigma-Aldrich, Taufkirchen, Germany) was used as 35\% aqueous solution.

The stone samples were commercial travertine (SC NATCOS SRL, Râmnicu Vâlcea, Romania) and were used as received (small, parallelepiped pieces). The stones were subjected to an ultrasonic treatment in distilled water for one hour, rinsed with deionised water and dried in an oven at $150{ }^{\circ} \mathrm{C}$ overnight. The XRD measurements performed on the stone samples were carried out on a Brucker-AXS Advance D8 diffractometer (Karlsruhe, Germany).

\subsection{The Silica Material Synthesis and Film Deposition}

A modified method based on the Strober synthesis [19] (hydrolytic alkaline route) was used to obtain the silica materials. In order to ensure an appropriate $\mathrm{pH}$ value, $35 \%$ ammonium hydroxide solution was used. The sol-gel synthesis was conducted in two steps, as follows (Scheme 1):

- Step 1: The preparation of silica nanoparticles from TEOS precursor;

- Step 2: Functionalisation of the silica nanoparticles with organo-modified silane precursors.

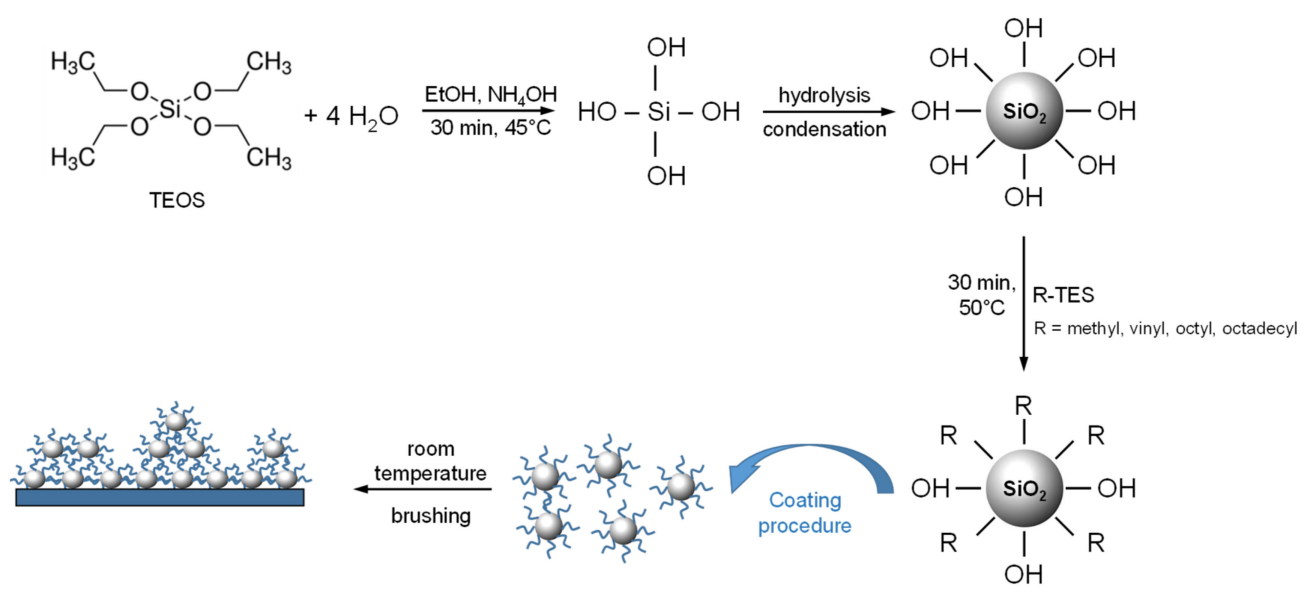

Scheme 1. Schematic representation of the synthesis of hybrid silica nanodispersion. 
Briefly, a typical synthesis starts with the preparation of the solvent mixture composed of ethanol and distilled water in an appropriate molar ratio (2.7/1), followed by the addition of the ammonium hydroxide solution in order to obtain an alkaline medium. The mixture is then heated at $40-45^{\circ} \mathrm{C}$, while magnetically stirred.

A mixture of $150 \mu \mathrm{L}$ TEOS and $400 \mu \mathrm{L}$ ethanol is added to the reaction solvent obtained in the first step, in order to ensure an ethanol/water/TEOS molar ratio of 138.06/72.24/1. About 5-10 min after adding the TEOS precursor, the mixture becomes slightly opalescent, indicating the forming of the silica particles. During this step, the temperature is kept at $45-50{ }^{\circ} \mathrm{C}$, and the mixture is magnetically stirred.

The organic functionalisation of the silica particles takes place when appropriate amounts of the coating precursor are added, dropwise, to the previous silica sol. The molar ratio between the TEOS and the organically modified precursor was $1.5 / 1$. The reaction takes place at a constant temperature of $50{ }^{\circ} \mathrm{C}$, under magnetic stirring. After synthesis and cooling at room temperature, the obtained materials were characterized and used to prepare the protective coatings. The dispersions containing functionalised silica particles were deposited onto solid surfaces by brushing, considering that this procedure is closest to the technique used by conservators. The films were dried for 5 days at room temperature. Similar silica films deposited on microscopy glass slides were used as model coatings.

\subsection{Characterisation}

\subsubsection{Characterisation of Silica Dispersions}

The silica dispersions obtained by the sol-gel method were investigated in order to determine the size of the particles, the stability and the film forming ability. The size and size distribution were measured using dynamic light scattering (DLS) on samples diluted in distilled water. The DLS measurements were performed on a MalvernNano ZS Zetasizer instrument (Malvern, UK) at $25^{\circ} \mathrm{C}$ with 2 min equilibration time, using glass cuvettes with square apertures. The reported diameters were the average of three measurements performed for each sample. The stability of the silica dispersions was investigated by visual observation and from the variation of particle diameter measured by DLS.

The FTIR spectra of the hybrid coating materials were measured using a Fourier Transformed Infrared spectrometer Tensor 37 (Bruker, Billerica, MA, USA), in the range $400-4000 \mathrm{~cm}^{-1}$, with a resolution of $4 \mathrm{~cm}^{-1}$. All hybrids silica samples were dried at room temperature and characterized as powders. The spectra were recorded in ATR transmission mode.

The film-forming ability of silica alcosol was evaluated from the aspect of the film deposited onto the glass and stone surface via visual inspection of the film's homogeneity.

The morphology of the obtained materials was investigated using a scanning electron microscope (SEM) Quanta 200 FEI (Amsterdam, The Netherlands), operating at an accelerating voltage of $30 \mathrm{kV}$. The samples were prepared by placing a drop of diluted dispersion on a carbon tape.

\subsubsection{Film Characterisation}

Characteristics of the coating films deposited onto solid surfaces were investigated to determine the morphology of the films, the optical properties and the water repellent characteristics. The chemical composition and crystallinity of the stone were investigated using XRF on a Panalytical X'pert PRO MPD equipment.

The Surface morphology of silica samples were imaged in the non-contact mode in air with a scan rate of $0.5 \mathrm{~Hz}$ and $256 \times 256$ pixels using SPM-NTegra Prima AFM (NT-MDT, Moscow, Russia) with an NSG 10 cantilever (resonance frequency: 190-325 kHz, elastic constant: 5.5-22.5 N/m). Silica nano-coatings were deposited on clean glass slides from the as-prepared materials and dried at room temperature. The roughness values of the films were calculated from the cross-sectional profile recorded. 
The wettability of the organo-modified silica films was determined both on a glass substrate and on the travertine stone. The measurements of both the static contact angle and the contact angle hysteresis were performed on an OCA20 contact angle tensiometer (Data Physics, Germany), equipped with a digital camera and automatic software for image analysis. The measurements were made at room temperature using water as the reference liquid. The hysteresis of the contact angle was measured using a "needle-in-drop" technique, increasing or decreasing the volume of the droplet ( $1 \mu \mathrm{L} / \mathrm{step})$. The value of hysteresis was determined as the difference between the advancing angle (considered as the maximum angle recorded during the droplet growth without changes in the contact area of the liquid droplet on the solid surface) and receding angle (considered as the lowest CA value when diminishing droplet volume) [20]. The reported average values for advancing and receding contact angles were obtained from three measurements performed in different areas of the sample surface.

The water repellent was evaluated using the Karsten pipe method [21], applied according to the Réunion Internationale des Laboratoires et Experts des Matériaux, systèmes de construction et ouvrages recommendations (RILEM II.4 test) recommendations. Basically, a vertical cylinder filled with water was attached to the surface of the stone material and the amount of water absorbed by the stone was determined after $90 \mathrm{~s}, 5 \mathrm{~min}$, and then every $5 \mathrm{~min}$ for an hour, by measuring the decrease in the volume of water from the graduated pipe. The initial water uptake (WU) was calculated both for the treated and untreated travertine, after $90 \mathrm{~s}$, and the average water uptake was calculated for both samples after $60 \mathrm{~min}$, considering a contact area of $0.1256 \times 10^{-4} \mathrm{~m}^{2}$ and using the following equations [22]:

$$
\begin{aligned}
W U_{90 \mathrm{~s}}\left(\mathrm{~g} / \mathrm{m}^{2} \cdot \mathrm{s}\right) & =\frac{m_{90 \mathrm{~s}}}{A \cdot \operatorname{tgss}_{0}} \\
W U_{3600 \mathrm{~s}}\left(\mathrm{~g} / \mathrm{m}^{2} \cdot \mathrm{s}\right) & =\frac{m_{3600 \mathrm{~s}}}{A \cdot 3 \cdot 3600 \mathrm{~s}}
\end{aligned}
$$

where $m_{90 s}$ and $m_{3600 s}$ are the amounts of water embedded in the solid sample after $90 \mathrm{~s}$ and $60 \mathrm{~min}$, respectively, $t$ is time and $A$ is the considered contact area between the stone and liquid.

The use of materials as treatments for cultural heritage artefacts requires minimum changes in the optical aspect (i.e., colour and gloss) of the monument. The modifications induced by the use of an organo-modified silica nanostructured film to travertine samples were measured using a Data Color 550 Spectrophotometer, with a d/8 $8^{\circ}$ geometry, in D65 (daylight), A10 (tungsten light) and F11 (fluorescent light) lighting conditions. The data were recorded on a sample of travertine, in the same area, before and after treatment with the silica hybrid material.

A short-term stability test was performed on the hybrid material from TEOS/ $\mathrm{O}_{8} \mathrm{TES}$ deposited on the travertine samples during outdoor exposure. The film was deposited using a brushing method as described before. The coated stone samples were measured in terms of water contact angles, in static and dynamic regime, before and after they were kept for a week in an open recipient outside the building on windowsill.

\section{Results and Discussions}

Water repellent is one of the main properties exhibited by hydrophobic and superhydrophobic surfaces. Some of these surfaces show other important characteristics that ensure superior resistance against weathering and bacterial attacks such as self-cleaning, anti-fouling, anti-graffiti [23] and anti-icing properties [24].

The effect of the chemical composition on the contact angle is limited due to the limitation of interfacial tension. Thus, for hydrocarbon compounds, the variation in surface chemical structures is insufficient to achieve high hydrophobicity [25]. Obtaining highly hydrophobic surfaces requires an appropriate surface roughness, which increases the contact angle in the case of hydrophobic materials as reported by Wenzel [26] and Cassie and Baxter [27].

Based on these considerations, a rational design was proposed to obtain a nanostructured silica film-forming material for the protective treatment of travertine stone. 
The composition of the stone was investigated in order to design a suitable protection coating compatible with the solid surface. In the present work, the travertine samples used as stone subjected to the protective treatment were analysed simply to confirm their chemical composition. Travertine rocks were used in the study as model calcareous historic material originating from Romanian traditional exploitation fields, well characterized and similar in properties to those of original monuments. The composition and morphology of the model stones were analysed by XRD spectroscopy and SEM, and the results are summarized in Figure 1. X-ray diffraction spectrum confirm the presence of calcite.

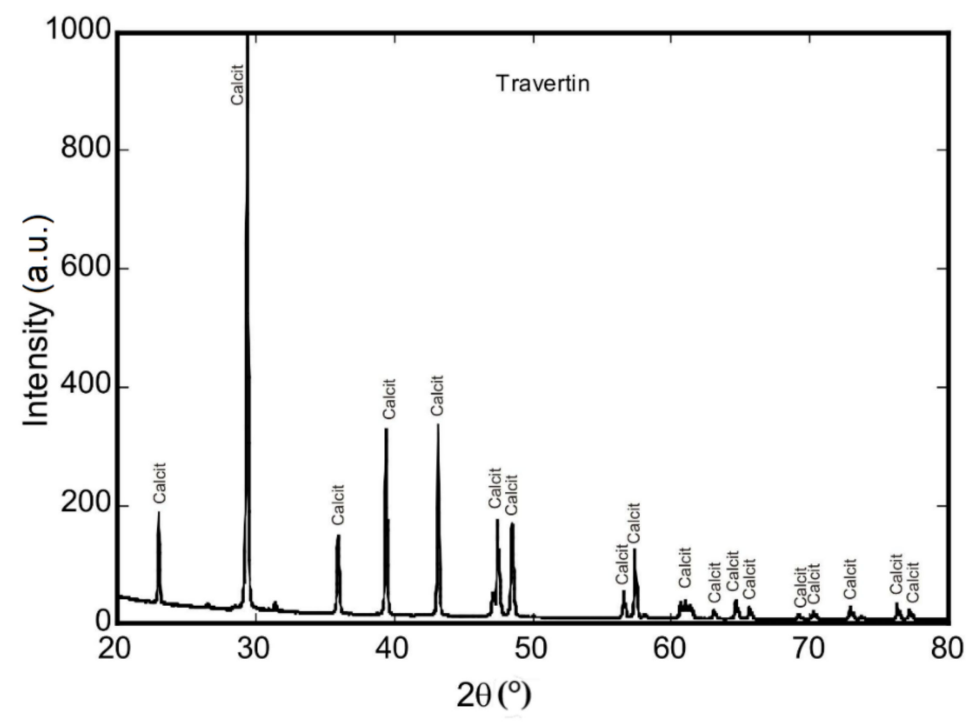

(a)

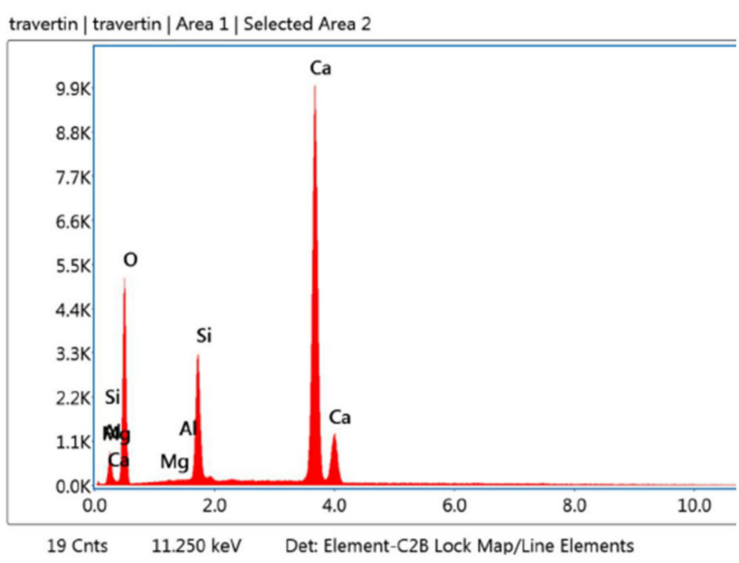

(b)

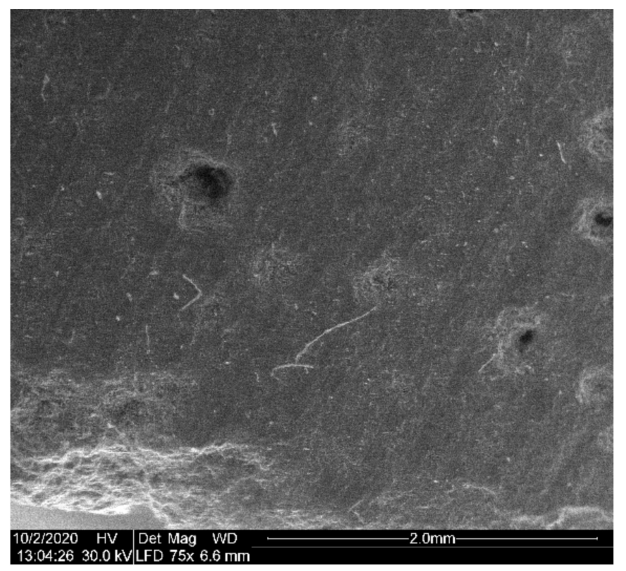

(c)

Figure 1. XRD travertine spectrum (a); SEM image of travertine commercial sample (b); EDX analysis of the same sample (c).

The commercial sample used as model travertine rock exhibited very rare large pores (like small holes with 10-100 $\mu \mathrm{m}$ diameter). The EDX spectra exhibited specific signals for $\mathrm{Ca}, \mathrm{C}$ and $\mathrm{O}$, which confirm the carbonate content, together with some traces of $\mathrm{Mg}, \mathrm{Al}$ and $\mathrm{Si}$ usually found in natural travertine.

The protective coatings were prepared as silica polymeric films with nanoparticles in order to achieve highly hydrophobic properties and preserve cost efficiency and facile processability of the material. In order to predict the hydrophobicity of the materials that were to be obtained, we previously analysed the hydrophobicity of the silanes used as silica-particle coatings. For this, the static contact angles were measured on silane-based polymeric surfaces containing only the modifying agent. 
The single silane precursor used in synthesis led to the formation of films with very low roughness; thus, the measured hydrophobicity was only due to the chemical composition of the substrate.

The preliminary investigations of the films from organo-modified silane derivatives used as modifying agents are summarised in Table 1 . The average roughness was determined from the AFM topography using the image analysis software (Nova 1494). The low values of average roughness ranging in the interval $0.45-7.00 \mathrm{~nm}$ prove that smooth films deposited on the glass surface can be obtained for all silane reagents.

Table 1. Average roughness of the films obtained using only silica particles modifying agents.

\begin{tabular}{ccccc}
\hline Silane Derivative & MTES & VTES & O $_{\mathbf{8}}$ TES & O $_{\mathbf{1 8}}$ TES \\
\hline Average roughness $(\mathrm{nm})$ & 0.45 & 1.70 & 3.50 & 7.00 \\
\hline
\end{tabular}

The static contact angle values of water on the films deposited onto model glass surfaces are presented in Table 2. The presented values were the result of three drops measured on different regions of the silane coating onto the solid substrate.

Table 2. The water static contact angle of the films containing only organo-modified silane derivatives.

\begin{tabular}{ccccc}
\hline Silane Derivative & MTES & VTES & O $_{\mathbf{8}}$ TES & O $_{18}$ TES \\
\hline Average CA $\left({ }^{\circ}\right)$ & $88.20 \pm 2.14$ & $92.07 \pm 3.26$ & $102.38 \pm 3.03$ & $101.37 \pm 2.53$ \\
\hline
\end{tabular}

The silica alcosol was prepared using TEOS as the nanoparticle precursor and performing the further functionalisation of the silica particles with various organo-modified silane derivatives in the second step. The polymerisation process of silane derivatives corresponds to those described in the literature [28].

The general aspect of the hybrid silica dispersions is summarized in Table 3.

Table 3. Characteristics of the hybrid silica materials.

\begin{tabular}{|c|c|c|c|}
\hline Sample & Optical Aspect & Stability of the Material & Film-Forming Capacity \\
\hline TEOS/MTES & Translucent (bluish) & $\begin{array}{l}\text { Material is stable in } \\
\text { the liquid phase }\end{array}$ & $\begin{array}{l}\text { Film-forming material; } \\
\text { the film is homogenous } \\
\text { but white and opaque }\end{array}$ \\
\hline TEOS/VTES & Translucent (bluish) & $\begin{array}{l}\text { Material is unstable and } \\
\text { turns to gel within } \\
24 \mathrm{~h} \text { of preparation }\end{array}$ & $\begin{array}{l}\text { Film-forming material only } \\
\text { when freshly prepared }\end{array}$ \\
\hline TEOS/O 18 TES & $\begin{array}{l}\text { Two phases, one solid } \\
\text { and white, and another } \\
\text { liquid and transparent }\end{array}$ & Unstable system & $\begin{array}{l}\text { Low film-forming capacity } \\
\text { even when fresh }\end{array}$ \\
\hline TEOS/O $/ \mathrm{O}_{8} \mathrm{TES}$ & Opaque & $\begin{array}{l}\text { Material is stable in the } \\
\text { liquid phase }\end{array}$ & $\begin{array}{l}\text { Film-forming material; } \\
\text { the film is homogenous } \\
\text { and transparent }\end{array}$ \\
\hline
\end{tabular}

During the first $24 \mathrm{~h}$ after the preparation of the materials, they were observed both in the liquid phase and as films. The hybrid material with VTES turned into gel within the first $24 \mathrm{~h}$ after the synthesis. The observations of the aging behaviour at room temperature led to the conclusion that this material did not have a potential use in the field of cultural heritage conservation; thus, it was not subjected to further investigations. The film based on MTES-modified silica particles was opaque and white, changing the aspect of the travertine sample and preventing its use as treatment for cultural heritage monuments. The material containing n-octadecyltriethoxysilane as a modifying agent was very unstable and could not be investigated further. Taking these factors into consideration, 
the only system that showed promising characteristics and warranted further studying was the one containing octyl-modified silica particles. The silane derivatives with long hydrocarbon chains (octyl and octadecyl) exhibited rather similar values for the water contact angle (Table 2); thus, both of them could be used as organo-modified components of the final coating material. Octyl triethoxy silane $\mathrm{O}_{8}$ TES was selected for further experiments, since it is more affordable and abundant and its hydrophobicity is one of the best.

It is generally accepted that the presence of nanoparticles in the material for stone treatment could favour the formation of more hydrophobic surface, with better water repellent, but the optical aspect was modified in terms of transparency and gloss. The solid content (i.e., number of nanoparticles) and the size of the particles in the dispersion are vital parameters in the process of optimizing the formulation of a new material for the protection of stones. [29].

The average size of the functionalized silica nanoparticles was $219 \mathrm{~nm}$, as shown in Figure 2, and the polydispersity index of the system was found to be 0.453 .

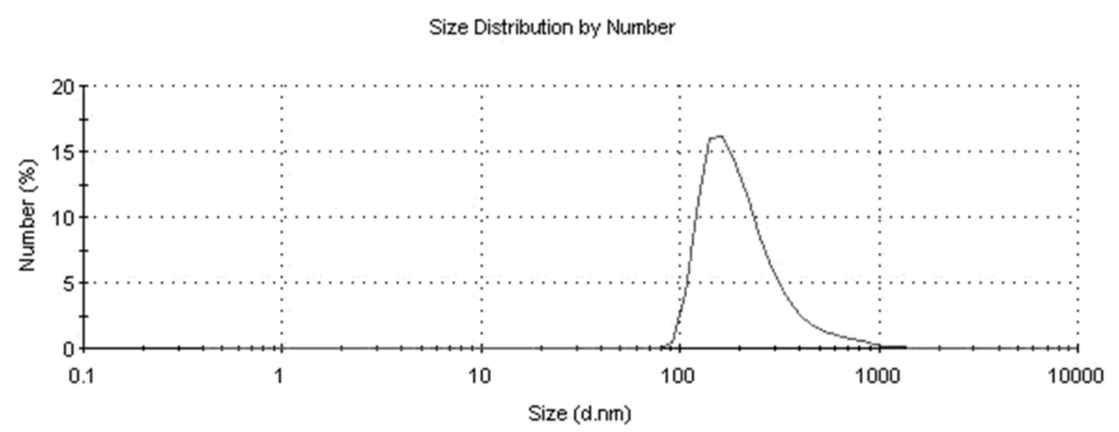

Figure 2. DLS diagram of the TEOS/O $\mathrm{O}_{8}$ TES based system.

The silica particles formed in the dispersion were found to be spherical and rather homogenous in size, as shown in the SEM image in Figure 3. The image confirms the information obtained from the DLS analysis regarding the dimensions and size distribution of the organo-modified silica spheres.

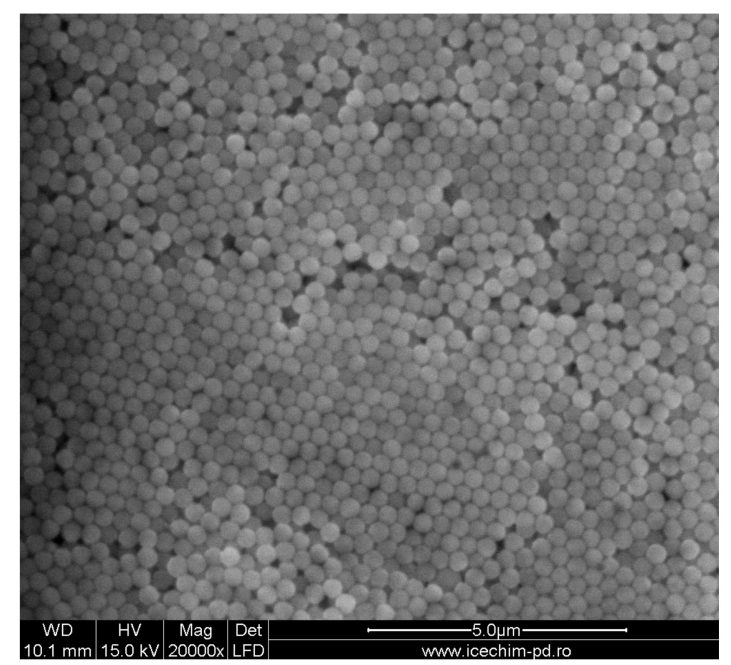

Figure 3. SEM image of the TEOS/O $\mathrm{O}_{8} \mathrm{TES}$ based system.

Organo-modified silica particles can form closely packed assemblies on surfaces due to the van der Waals interactions that generate the roughness of the substrates. The morphology of the film formed by brushing the silica dispersions onto the glass slides used as solid support was investigated considering that it is essential for the behaviour of the coating material on the stone. 
Figure 4 presents the morphology, the topography and the phase contrast of the obtained material showing typical AFM images for the octyl-modified film deposited onto glass slides.
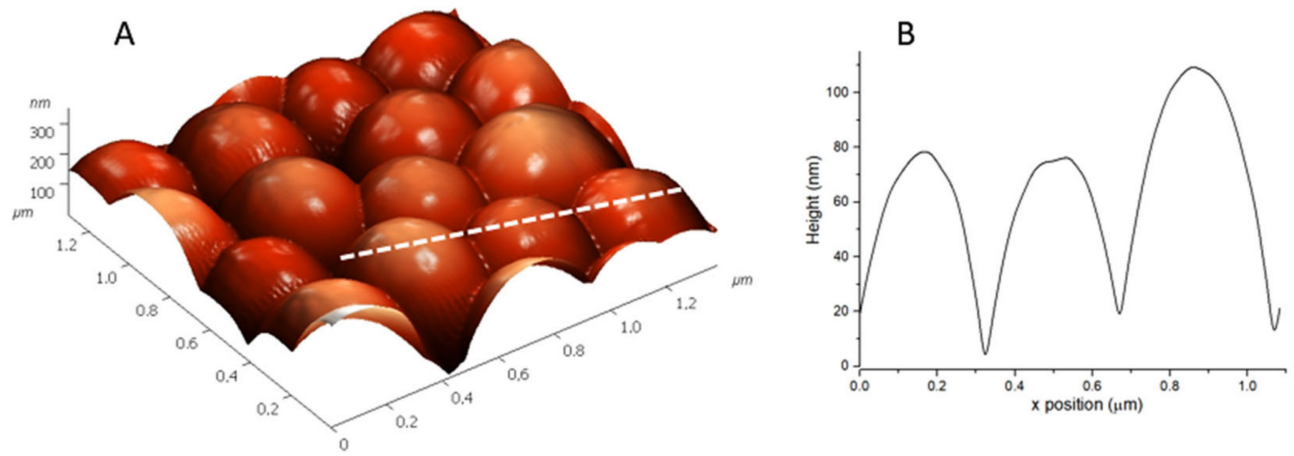

Figure 4. 3D-AFM image of TEOS/O $\mathrm{O}_{8}$ TES hybrid film deposited on clean glass slide (A) and cross-section corresponding to the dotted line (B).

As the images show, the nanostructured film was formed of spherical, uniformly distributed organo-modified silica particles. The phase contrast image shows spheres that have a darker core and a lighter shell, proving the presence of octyl chains coating the silica particles. These hydrocarbonate chains assure some degree of hydrophobicity to the film, due to the fact of their chemical character. As it is shown from the contact angle values for smooth films prepared with a single precursor in sol-gel synthesis, the hydrophobicity of octyl and octadecyl-modified surfaces was similar (CA around $\left.100^{\circ}\right)$ and far to the superhydrophobic region $\left(150^{\circ}\right)$. For a further increase in the contact angle values recorded on hybrid silica films, nanostructured surface was responsible, induced by the presence of nanoparticles.

The chemical composition of the hybrid organo-modified materials was investigated and FTIR spectra are presented in Figure 5. The formation of the silica network and presence of alkyl groups is confirmed, in agreement with previously published data [30].

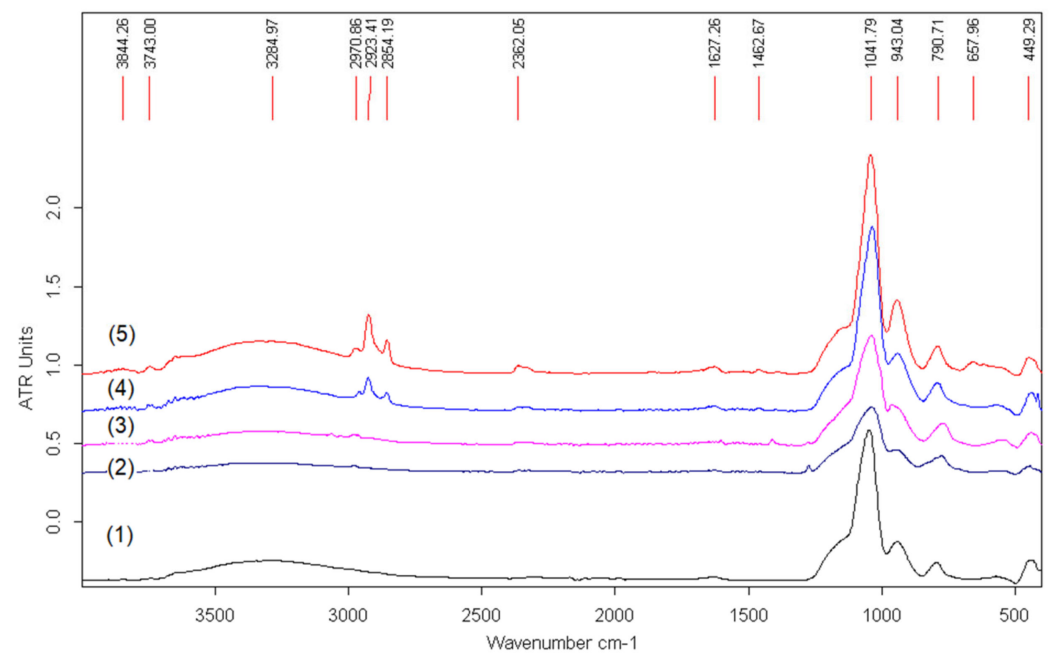

Figure 5. FTIR-ATR spectra of organo-modified silica hybrid material with various precursor compositions: (1) TEOS reference material, (2) TEOS/MTES, (3) TEOS/VTES, (4) TEOS/O 8 TES and (5) TEOS $/ \mathrm{O}_{18}$ TES.

In all spectra, strong absorption bands can be observed in the region $\sim 1040 \mathrm{~cm}^{-1}$ due to the presence of the asymmetric stretching vibration of $\mathrm{Si}-\mathrm{O}-\mathrm{Si}$ bonds, thus confirming the formation of the siloxane network. The $\mathrm{Si}-\mathrm{OH}$ bonds were responsive for the peak at $\sim 940 \mathrm{~cm}^{-1}$, and also present in the spectra of all prepared silica materials. 
For the reference material obtained only with TEOS, a broad absorption band around $3280 \mathrm{~cm}^{-1}$, corresponded to the overlapped signals of the $-\mathrm{OH}$ stretching bands of adsorbed water and $\mathrm{SiO}-\mathrm{H}$ stretching of silanol groups from the surface, indicating the hydrophilic nature of the silica film. In the case of the hybrid films, this peak was less intense and shifted toward a higher wavenumber.

For the silica materials containing precursors with long chain alkyl chains (i.e., $\mathrm{C}_{8} \mathrm{TES}$ and $\mathrm{C}_{18}$ TES) peaks at 2850 and $2920 \mathrm{~cm}^{-1}$ were found corresponding, respectively, to the symmetric and asymmetric stretching vibration in the $\mathrm{CH}_{2}$ groups [31]. The signals in this region were extremely weak for the hybrid films with MTES and VTES derivatives due to the very low content of organic-modified precursors (low TEOS/RTES molar ratio).

The analysis of FTIR spectra, proved that the hydrolysis and polycondensation reactions between the TEOS and organo-modified silane precursors successfully occurred. The decrease in the intensity and shift of the absorption band around $3200 \mathrm{~cm}^{-1}$, together with the increase of $\mathrm{C}-\mathrm{H}$ stretching bands demonstrate the replacement of $\mathrm{Si}-\mathrm{OH}$ groups from the surfaces with nonhydrolyzable Si-alkyl groups, thus the increase of the hydrophobicity of the obtained material.

Static contact angle measurements were performed on hybrid films obtained using a mixture of TEOS and organo-modified silica derivatives in order to confirm the supposition that the octyl-modified silica-based nanostructured coating would yield the highest contact angle value. The results are summarised in Table 4.

Table 4. Water static contact angles measured on various hybrid films deposited onto glass slides.

\begin{tabular}{ccccc}
\hline Silane Derivative & TEOS/MTES & TEOS/VTES & TEOS/O $_{\mathbf{8}}$ TES & TEOS/O $_{\mathbf{1 8}}$ TES \\
\hline Average CA $\left(^{\circ}\right)$ & $96.90 \pm 2.21$ & $100.17 \pm 1.42$ & $145.63 \pm 1.04$ & $139.90 \pm 2.56$ \\
\hline
\end{tabular}

The highest value of contact angle was obtained for the hybrid silica polymer containing the $\mathrm{O}_{8}$ TES derivative, while the rather unexpected low value was measured for the $\mathrm{O}_{18}$ TES silane derivative with the longer hydrocarbon chain. The differences between the hydrophobicity of the deposited films containing $\mathrm{O}_{8}$ TES and $\mathrm{O}_{18}$ TES silane functionalisation agents may have resulted from the variation of the hydrocarbon chains' proportions in the mixture and from local variations of the roughness in deposited coatings. The unexpected hydrophobic properties of hybrid material with TEOS/O ${ }_{18}$ TES compositions, lower than the one with $\mathrm{O}_{8}$ TES, was probably due to the specific morphologies of the films prepared from octadecyl silane precursor, which was also reported in other papers [32]. The SEM images of the nanostructured films obtained using octadecyl silanes, reported by Barrera et al. [32], demonstrated the presence of a mixture of spherical nanoparticles and lamellar structures, responsible for the decrease of contact angle values.

The contact angle measurements, both static and dynamic, were performed on the octyl-modified silica film, deposited onto travertine stone. The data obtained from these measurements are presented in Table 5.

Table 5. Static water contact angle (CA) measurements and contact angle hysteresis on travertine samples covered with octyl-modified silica nanostructured film.

\begin{tabular}{cccccc}
\hline $\begin{array}{c}\text { Static CA } \\
\left({ }^{\circ}\right)\end{array}$ & $\begin{array}{c}\text { Advancing CA } \\
\left(\mathbf{(}^{\circ}\right)\end{array}$ & $\begin{array}{c}\text { Receding CA } \\
\left({ }^{\circ}\right)\end{array}$ & $\begin{array}{c}\text { CA Hysteresis } \\
\left({ }^{\circ}\right)\end{array}$ & $\begin{array}{c}\text { Average CA } \\
\left(\mathbf{(}^{\circ}\right)\end{array}$ & $\begin{array}{c}\text { Average Hysteresis } \\
\left({ }^{\circ}\right)\end{array}$ \\
\hline 146.7 & 147.7 & 142.6 & 5.1 & & \\
145.9 & 146.5 & 142.1 & 4.4 & $146.56 \pm 1.16$ & $5.07 \pm 1.44$ \\
147.1 & 148.9 & 143.2 & 5.7 & & \\
\hline
\end{tabular}

Figures 6 and 7 show the images captured during water contact angle hysteresis measurement on coated travertine. The wettability measurements show that the nanostructured octyl-modified silica particles formed a highly hydrophobic coating on the travertine stone, exhibiting a contact angle value close to superhydrophobicity and with low values of hysteresis. 


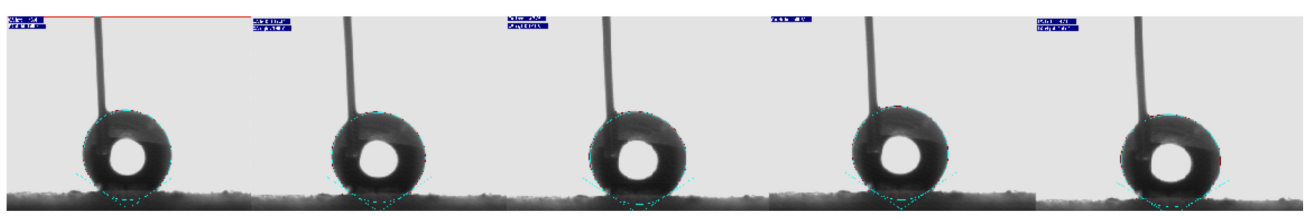

Figure 6. The contact angle increased to the advancing contact angle measured on the travertine stone coated with the octyl-modified silica nanostructured film.

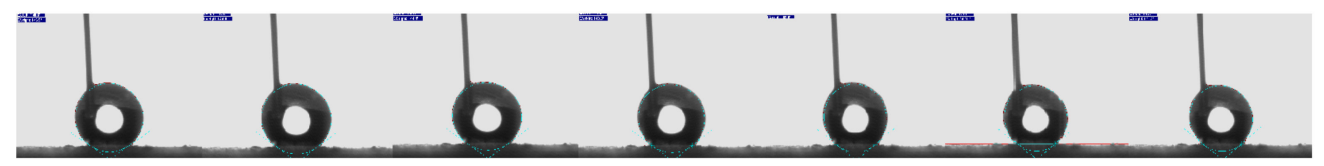

Figure 7. The contact angle decreased to the receding contact angle measured on the travertine stone coated with octyl-modified silica nanostructured film.

Since the value of the contact angle was the highest for the TEOS/O $\mathrm{O}_{8} \mathrm{TES}$ system, and the hysteresis values were satisfactory, this material was considered best suited for the water repellent treatment of the travertine stone.

The protective coatings with highly hydrophobic properties act as a barrier to inhibit the contact of moisture with the original material of the historic building or monument. A high value of the water contact angle that ensures minimum contact between the water droplet and the stone, together with a small value of the sliding contact angle are the requirements for an effective treatment. The values of the water contact angle (WCA) obtained for the travertine coated with the TEOS/ $\mathrm{O}_{8}$ TES film are close to the superhydrophobic regime, with reduced hysteresis; thus, one could expect a significant decrease in the humidity impact on the stone.

The morphology of the deposited hybrid silica film with TEOS/O $/ \mathrm{O}_{8} \mathrm{TES}$ on commercial samples of travertine was investigated by SEM. The images of the pristine stone surface and the stone coated with TEOS/O 8 TES film are shown in Figure 8.

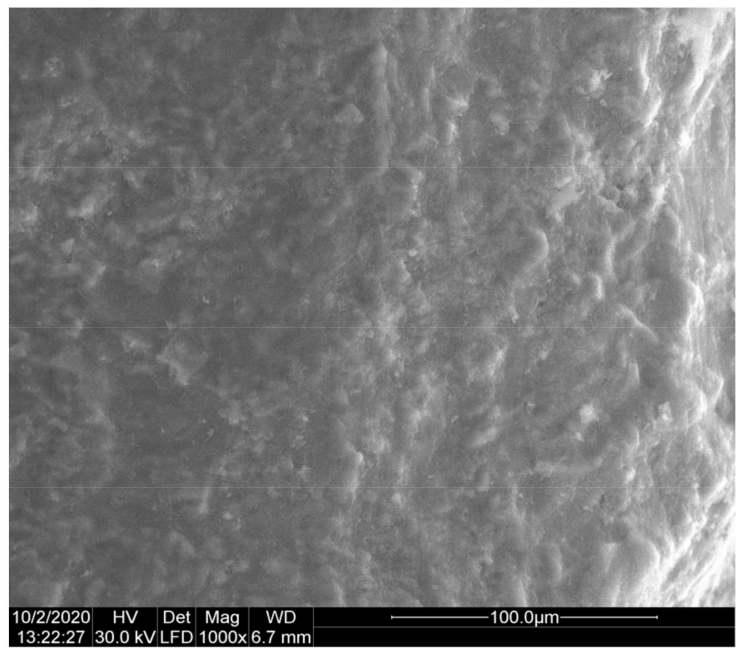

(a)

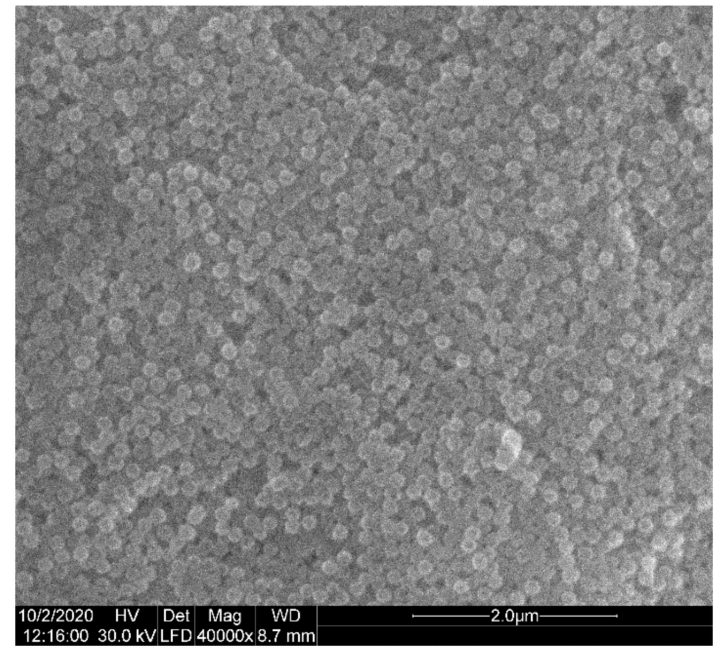

(b)

Figure 8. SEM images of the travertine sample: pristine stone (a); travertine coated with TEOS/ $\mathrm{O}_{8}$ TES hybrid material (b).

As is evidenced in the SEM image, the nanostructured coating deposited had a uniform structure without craquelures. 
The presence of quasi spherical silica nanoparticles on the surface of the travertine sample coated with the hybrid material was observed. The brushing method, usually used for coating deposition in conservation procedures, enables the formation of multiple layers of nanoparticles. The resulting microand nanoscale roughness of the surface, together with the hydrophobicity of the organo-modified silane component $\mathrm{O}_{8}$ TES explain the high values obtained for the water contact angles.

The quality of the protective barrier formed by the TEOS/ $\mathrm{O}_{8} \mathrm{TES}$ films was evaluated from the water absorption behaviour using the Karsten pipe method. The data regarding the amount of absorbed water by the treated stone compared to the untreated one over the same period of time are presented in Table 6.

Table 6. Water absorption (initial and average) calculated using the Karsten pipe method for both coated and uncoated travertine.

\begin{tabular}{ccc}
\hline Parameter & Value \\
\hline $\begin{array}{c}\text { Initial water absorption on the } \\
\text { untreated travertine }(90 \mathrm{~s})\end{array}$ & $W U_{90 \mathrm{~s}}=\frac{m_{90 \mathrm{~s}}}{A \cdot t_{90 \mathrm{~s}}}=\frac{1.9 \times 10^{-3} \mathrm{~g}}{0.1256 \times 10^{-4} \mathrm{~m}^{2} \times 90 \mathrm{~s}}=1.6808 \mathrm{~g} / \mathrm{m}^{2} \cdot \mathrm{s}$ \\
\hline $\begin{array}{c}\text { Initial water absorption on the } \\
\text { treated travertine }(90 \mathrm{~s})\end{array}$ & $W U_{90 \mathrm{~s}}=\frac{m_{90 \mathrm{~s}}}{A \cdot t_{90 \mathrm{~s}}}=\frac{0.2 \times 10^{-3} \mathrm{~g}}{0.1256 \times 10^{-4} \mathrm{~m}^{2} \times 90 \mathrm{~s}}=0.1769 \mathrm{~g} / \mathrm{m}^{2} \cdot \mathrm{s}$ \\
\hline $\begin{array}{c}\text { Average water absorption on the } \\
\text { untreated travertine }(1 \mathrm{~h})\end{array}$ & $W U_{3600 \mathrm{~s}}=\frac{m_{3600 \mathrm{~s}}}{A \cdot t_{3600 \mathrm{~s}}}=\frac{2.9 \times 10^{-3} \mathrm{~g}}{0.1256 \times 10^{-4} \mathrm{~m}^{2} \times 3600 \mathrm{~s}}=0.0641 \mathrm{~g} / \mathrm{m}^{2} \cdot \mathrm{s}$ \\
\hline $\begin{array}{c}\text { Average water absorption on the } \\
\text { treated travertine }(1 \mathrm{~h})\end{array}$ & $W U_{3600 \mathrm{~s}}=\frac{m_{3600 \mathrm{~s}}}{A \cdot t_{3600 \mathrm{~s}}}=\frac{0.9 \times 10^{-3} \mathrm{~g}}{0.1256 \times 10^{-4} \mathrm{~m}^{2} \times 3600 \mathrm{~s}}=0.0199 \mathrm{~g} / \mathrm{m}^{2} \cdot \mathrm{s}$ \\
\hline
\end{tabular}

The diagram in Figure 9 shows the behaviour of the treated travertine versus the untreated one in what concerns absorption through capillarity. The covered travertine exhibits much lower water absorption and also a tendency towards stabilisation, meaning that the water absorption stops. The uncoated travertine samples show no such behaviour and the water uptake is also much higher.

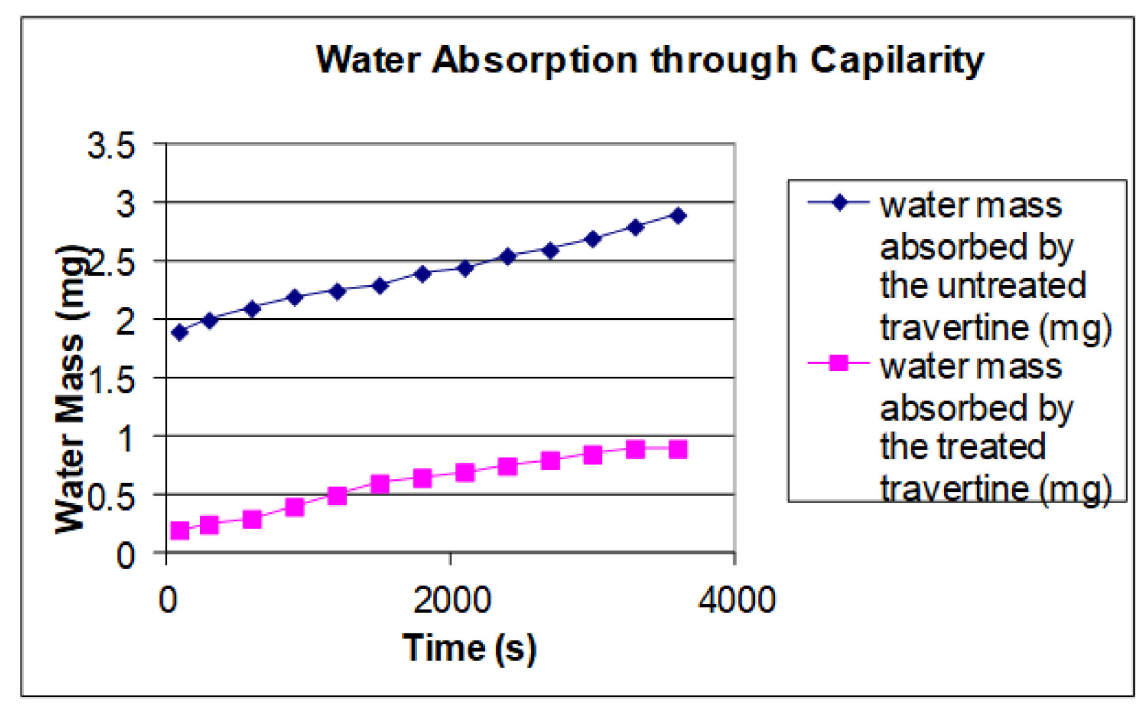

Figure 9. Water absorbed by the untreated and treated travertine within $1 \mathrm{~h}$

After depositing the chosen film onto the travertine, no changes in the colour or gloss of the stone were observed. Figure 10 shows a sample of travertine stone; the left side was covered with nanostructured octyl-modified silica film and the right side was not. No optical differences were observed between the two. 


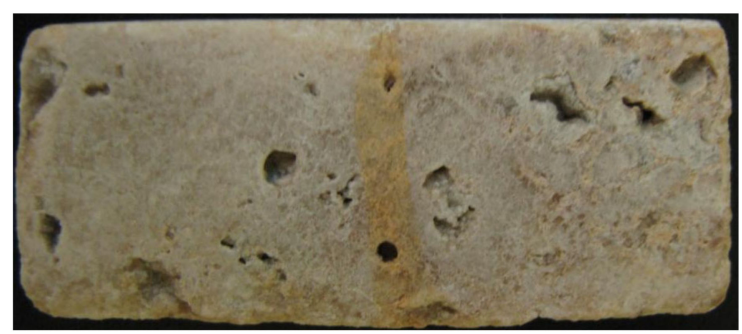

Figure 10. Visual aspect of the coated (left) and uncoated (right) travertine stone.

The chromatic changes induced by the deposition of coating silica hybrid material may exist, even though they are not obvious to the naked eye. In order to obtain a better evaluation of the changes in gloss and colour that the travertine samples undergo, colorimetric measurements were performed. The results are summarized in Table 7 , where $L^{*}, a^{*}$ and $b^{*}$ are the colour coordinates lightness, green-red and blue-yellow coordinates, respectively, and $\Delta E^{*}$ represent the overall colour difference.

Table 7. Colour and gloss variations of the coated travertine measured according to the CIELAB colour space.

\begin{tabular}{cccccc}
\hline \multirow{2}{*}{ Lighting Conditions } & \multirow{2}{*}{ Sample } & \multicolumn{3}{c}{ Parameter } & \multirow{2}{*}{ Total Variation $\Delta E^{*}$} \\
\cline { 3 - 5 } & & $\boldsymbol{L}^{*}$ & $\boldsymbol{a}^{*}$ & $\boldsymbol{b}^{*}$ & \\
\hline \multirow{2}{*}{ D65 (day light) } & Uncoated travertine & 82.92 & 3.02 & 9.23 & \multirow{2}{*}{1.72} \\
& Coated travertine & 84.17 & 2.61 & 8.12 & \multirow{2}{*}{1.80} \\
\multirow{2}{*}{ A10 (tungsten light) } & Uncoated travertine & 83.89 & 5.03 & 10.36 & \multirow{2}{*}{1.80} \\
& Coated travertine & 85.02 & 4.37 & 9.12 & 10.50 \\
\hline \multirow{2}{*}{ F11 (fluorescent light) } & Uncoated travertine & 83.48 & 3.23 & 1.50 \\
& Coated travertine & 84.66 & 2.76 & 9.22 & \\
\hline
\end{tabular}

Although some changes in colour and gloss occur $\left(\Delta E^{*} \neq 0\right)$, they are not perceived by the human eye, since, according to the CIELAB system, humans notice modifications for $\Delta E^{*} \geq 10$ [33]. The obtained material fits well with the accepted values for optical changes. The highest interest in this case is for stone monuments displayed outdoors; therefore, D65 lighting conditions require more attention. It is obvious that the total colour and gloss variation is very small and that the highest difference appears for the $L^{*}$ component, the one representing the gloss of the surface. This can be easily explained by the presence of silica nanoparticles, known to have a luminosity coefficient of 88 , higher than that of clean travertine.

Coating materials prepared from commercially available silica nanoparticles in silicate matrix was reported in literature. The results of their stability test under the outdoor exposure, during four month, proved to be encouraging [34]. Thus, small changes (less than $15^{\circ}$ ) were observed at the values of static water contact angles on limestone and sandstone treated samples, in contrast with granite, where notable changes (up to $60^{\circ}$ ) were recorded. Significant variation of the stability test results have been reported in the same paper, for films with different content of nanoparticles and siloxane matrix. This means that extensive studied are needed in order to formulate a general conclusion on the durability of nanostructured silica films.

A preliminary test on the stability of the proposed material was performed in order to evaluate the quality of the coating. The water contact angles and hysteresis were measured on the nanostructured films deposited on travertine samples and the average values are summarized in Table 8 . 
Table 8. The water static contact angle and hysteresis on the travertine coated with TEOS/O $\mathrm{O}_{8} \mathrm{TES}$ films before and after outdoor exposure.

\begin{tabular}{ccc}
\hline Sample & Average CA $\left(^{\circ}\right)$ & CA Hysteresis $\left(^{\circ}\right.$ ) \\
\hline Coated travertine before exposure & $146.76 \pm 1.62$ & $5.23 \pm 0.90$ \\
Coated travertine after 7 day exposure & $144.43 \pm 0.94$ & $7.27 \pm 0.79$ \\
\hline
\end{tabular}

A preliminary test was performed over a week. In this time, no rainfall was recorded. Only temperature variations $\left(15\right.$ to $\left.32{ }^{\circ} \mathrm{C}\right)$ and moderate humidity over the night were the factors which affected the organo-modified coating. In these conditions, almost no reduction in the value of the average water contact angle was recorded, while the contact angle hysteresis increased from $5.23^{\circ}$ to $7.27^{\circ}$. Also, the wettability properties of the film with octyl organo-modified silane remained quasi unchanged after an exposure in ambient conditions for 7 days. The long-term stability of the coating material should be investigated for the restoration treatment, but in close relationship with the real stone to be protected and in accordance with the specific conditions of the exposure.

Based on the results of the chromatic changes after deposition and minor variations of the wettability after short-term exposure to outdoor conditions, the performances of the proposed material were comparable to those reported by various authors for some widely used, commercially available water repellent treatments [35,36].

\section{Conclusions}

Polymeric silica nanomaterials were synthesized using various organo-modified silane derivatives, in order to obtain efficient coatings for travertine stone protection. Silica hybrid nanostructured materials were obtained through a two-step sol-gel method. The size, shape and stability of silica were investigated. The films deposited onto solid surfaces proved to be formed by the self-assembling process of silica nanoparticles. Considering the general characteristics of the silica dispersions and the thin films, the octyl-modified material proved to be the most suitable as a protective coating for travertine stone.

The AFM analyses confirmed that the hydrocarbonate octyl chains formed a shell around the silica particles, as it was intended in the original design of the material.

The contact angle measurements showed an increase in the hydrophobicity of coating material with the increase of the hydrophobic moiety in the organo-modified silane precursor. The wettability behaviour of $\mathrm{O}_{8}$ TES/TEOS system proved that this film was highly hydrophobic and assured the water repellent properties of the coated travertine stone, due both to surface roughness and to chemical composition.

The material is compatible with the travertine stone, and its application produces no significant modification of the stone's optical properties. The ageing behaviour of the obtained material needs to be further investigated on a collection of travertine stones from various areas in order to evaluate the long-term interaction with stone's surface, taking into account the huge variety of characteristics in these natural rocks. However, the obtained nanostructured material has high potential for use in the conservation of cultural heritage monuments made of travertine stone, due to the simplicity in fabrication, cost efficiency, and absence of fluorinated toxic components.

Author Contributions: Conceptualization, C.P. and L.O.C.; methodology, L.O.C.; validation, C.P. and L.O.C.; formal analysis, E.A., A.B., M.A.T. and L.O.C.; investigation, C.P. and L.O.C.; writing-original draft preparation, C.P. and L.O.C.; writing-review and editing, C.P. and L.O.C.; supervision, C.P. All authors have read and agreed to the published version of the manuscript.

Funding: This work was supported by grants from the Romanian National Authority for Scientific Research and Innovation, CCCDI-UEFISCDI, project number: PN-III-P1-1.2-PCCDI-2017-0743 and project number: PN-III-P1-1.2-PCCDI-2017-0428 (PC2), within PNCDI III.

Conflicts of Interest: The authors declare no conflict of interest. 


\section{References}

1. Sesana, E.; Gagnon, A.S.; Bonazza, A.; Hughes, J.J. An integrated approach for assessing the vulnerability of World Heritage Sites to climate change impacts. J. Cult. Herit. 2020, 41, 211-224. [CrossRef]

2. American Geological Institute. Dictionary of Mining, Mineral, and Related Terms; Springer-Verlag GmbH \& Co. KG: Berlin, Germany, 2003; ISBN 978-3-540-01271-9.

3. Urosevic, M.; Sebastián-Pardo, E.; Cardell, C. Rough and polished travertine building stone decay evaluated by a marine aerosol ageing test. Constr. Build. Mater. 2010, 24, 1438-1448. [CrossRef]

4. Chelmus, A.; Radvan, R.; Angheluta, L. Aerial Investigations Corroboration for Archaeology and Monuments. In Proceedings of the 2018 11th International Conference on Developments in eSystems Engineering (DeSE); IEEE: Cambridge, UK, 2018; pp. 113-116.

5. Advanced Materials for the Conservation of Stone; Hosseini, M.; Karapanagiotis, I. (Eds.) Springer International Publishing: Cham, Switzerland, 2018; ISBN 978-3-319-72259-7.

6. Benavente, D.; Martinez-Martinez, J.; Cueto, N.; Ordoñez, S.; Garcia-del-Cura, M.A. Impact of salt and frost weathering on the physical and durability properties of travertines and carbonate tufas used as building material. Environ. Earth Sci. 2018, 77, 147. [CrossRef]

7. Caneva, G.; Fidanza, M.R.; Tonon, C.; Favero-Longo, S.E. Biodeterioration Patterns and Their Interpretation for Potential Applications to Stone Conservation: A Hypothesis from Allelopathic Inhibitory Effects of Lichens on the Caestia Pyramid (Rome). Sustainability 2020, 12, 1132. [CrossRef]

8. Artesani, A.; Di Turo, F.; Zucchelli, M.; Traviglia, A. Recent Advances in Protective Coatings for Cultural Heritage-An Overview. Coatings 2020, 10, 217. [CrossRef]

9. Ruffolo, S.A.; La Russa, M.F. Nanostructured Coatings for Stone Protection: An Overview. Front. Mater. 2019, 6, 147. [CrossRef]

10. Fracture and Failure of Natural Building Stones; Kourkoulis, S.K. (Ed.) Springer: Dordrecht, The Netherlands, 2006; ISBN 978-1-4020-5076-3.

11. Vinçotte, A.; Beauvoit, E.; Boyard, N.; Guilminot, E. Effect of solvent on PARALOIDßB72 and B44 acrylic resins used as adhesives in conservation. Herit. Sci. 2019, 7, 42. [CrossRef]

12. Karapanagiotis, I.; Chatzigrigoriou, A.; Manoudis, P.N. Waterborne superhydrophobic coatings for the conservation of the cultural heritage. In Handbook of Waterborne Coatings; Elsevier: Amsterdam, The Netherlands, 2020; pp. 229-247, ISBN 978-0-12-814201-1.

13. Sabatini, V.; Pargoletti, E.; Comite, V.; Ortenzi, M.A.; Fermo, P.; Gulotta, D.; Cappelletti, G. Towards Novel Fluorinated Methacrylic Coatings for Cultural Heritage: A Combined Polymers and Surfaces Chemistry Study. Polymers 2019, 11, 1190. [CrossRef] [PubMed]

14. Wang, P.; Wei, W.; Li, Z.; Duan, W.; Han, H.; Xie, Q. A superhydrophobic fluorinated PDMS composite as a wearable strain sensor with excellent mechanical robustness and liquid impalement resistance. J. Mater. Chem. A 2020, 8, 3509-3516. [CrossRef]

15. Karapanagiotis, I.; Pavlou, A.; Manoudis, P.N.; Aifantis, K.E. Water repellent ORMOSIL films for the protection of stone and other materials. Mater. Lett. 2014, 131, 276-279. [CrossRef]

16. Cao, Y.; Salvini, A.; Camaiti, M. Superhydrophobic fluorinated oligomers as protective agents for outdoor stone artworks. J. Cult. Herit. 2020, 44, 90-97. [CrossRef]

17. Henry, B.J.; Carlin, J.P.; Hammerschmidt, J.A.; Buck, R.C.; Buxton, L.W.; Fiedler, H.; Seed, J.; Hernandez, O. A critical review of the application of polymer of low concern and regulatory criteria to fluoropolymers: Fluoropolymers PLC. Integr. Environ. Assess. Manag. 2018, 14, 316-334. [CrossRef] [PubMed]

18. Aslanidou, D.; Karapanagiotis, I. Superhydrophobic, Superoleophobic and Antimicrobial Coatings for the Protection of Silk Textiles. Coatings 2018, 8, 101. [CrossRef]

19. Stöber, W.; Fink, A.; Bohn, E. Controlled growth of monodisperse silica spheres in the micron size range. J. Colloid Interface Sci. 1968, 26, 62-69. [CrossRef]

20. Eral, H.B.; Oh, J.M. Contact angle hysteresis: A review of fundamentals and applications. Colloid Polym. Sci. 2013, 291, 247-260. [CrossRef]

21. Drdácký, M.; Slížková, Z. Enhanced affordable methods for assessing material characteristics and consolidation effects on stone and mortar. J. Geophys. Eng. 2013, 10, 064005. [CrossRef] 
22. Vandevoorde, D.; Pamplona, M.; Schalm, O.; Vanhellemont, Y.; Cnudde, V.; Verhaeven, E. Contact sponge method: Performance of a promising tool for measuring the initial water absorption. J. Cult. Herit. 2009, 10, 41-47. [CrossRef]

23. Lafuma, A.; Quéré, D. Superhydrophobic states. Nat. Mater. 2003, 2, 457-460. [CrossRef]

24. Liu, Y.; Song, D.; Choi, C.-H. Anti- and De-Icing Behaviors of Superhydrophobic Fabrics. Coatings 2018, 8, 198. [CrossRef]

25. Das, S.; Kumar, S.; Samal, S.K.; Mohanty, S.; Nayak, S.K. A Review on Superhydrophobic Polymer Nanocoatings: Recent Development and Applications. Ind. Eng. Chem. Res. 2018, 57, 2727-2745. [CrossRef]

26. Wenzel, R.N. Surface Roughness and Contact Angle. J. Phys. Colloid Chem. 1949, 53, 1466-1467. [CrossRef]

27. Cassie, A.B.D.; Baxter, S. Wettability of porous surfaces. Trans. Faraday Soc. 1944, 40, 546. [CrossRef]

28. Issa, A.; Luyt, A. Kinetics of Alkoxysilanes and Organoalkoxysilanes Polymerization: A Review. Polymers 2019, 11, 537. [CrossRef] [PubMed]

29. Manca, M.; Cannavale, A.; De Marco, L.; Aricò, A.S.; Cingolani, R.; Gigli, G. Durable Superhydrophobic and Antireflective Surfaces by Trimethylsilanized Silica Nanoparticles-Based Sol-Gel Processing. Langmuir 2009, 25, 6357-6362. [CrossRef] [PubMed]

30. Purcar, V.; Cinteza, O.; Donescu, D.; Bala, D.; Ghiurea, M.; Petcu, C.; Caprarescu, S. Surface modification of silica particles assisted by $\mathrm{CO}_{2}$. J. Supercrit. Fluids 2014, 87, 34-39. [CrossRef]

31. Parale, V.G.; Mahadik, D.B.; Mahadik, S.A.; Kavale, M.S.; Wagh, P.B.; Gupta, S.C.; Rao, A.V. OTES modified transparent dip coated silica coatings. Ceram. Int. 2013, 39, 835-840. [CrossRef]

32. Barrera, E.G.; Livotto, P.R.; Santos, J.H.Z. dos Hybrid silica bearing different organosilanes produced by the modified Stöber method. Powder Technol. 2016, 301, 486-492. [CrossRef]

33. Choudhury, A.K.R. Principles of Colour Appearance and Measurement; Woodhead Publishing Series in Textiles; Woodhead Publishing Limited in association with The Textile Institute: Sawston, UK, 2014; ISBN 978-0-85709-229-8.

34. De Ferri, L.; Lottici, P.P.; Lorenzi, A.; Montenero, A.; Salvioli-Mariani, E. Study of silica nanoparticles-polysiloxane hydrophobic treatments for stone-based monument protection. J. Cult. Herit. 2011, 12, 356-363. [CrossRef]

35. García, O.; Malaga, K. Definition of the procedure to determine the suitability and durability of an anti-graffiti product for application on cultural heritage porous materials. J. Cult. Herit. 2012, 13, 77-82. [CrossRef]

36. Tsakalof, A.; Manoudis, P.; Karapanagiotis, I.; Chryssoulakis, I.; Panayiotou, C. Assessment of synthetic polymeric coatings for the protection and preservation of stone monuments. J. Cult. Herit. 2007, 8, 69-72. [CrossRef]

Publisher's Note: MDPI stays neutral with regard to jurisdictional claims in published maps and institutional affiliations.

(C) 2020 by the authors. Licensee MDPI, Basel, Switzerland. This article is an open access article distributed under the terms and conditions of the Creative Commons Attribution (CC BY) license (http://creativecommons.org/licenses/by/4.0/). 